\title{
Empirical treatment with doxycycline of fever of intermediate duration
}

\author{
Emilio Guirao-Arrabal ${ }^{1}$ (1) - Leopoldo Muñoz-Medina ${ }^{1} \cdot$ Francisco Anguita-Santos $^{1} \cdot$ David Vinuesa-García $^{1}$. \\ José Hernández-Quero ${ }^{1}$
}

Received: 24 April 2021 / Accepted: 20 July 2021 / Published online: 30 July 2021

(c) The Author(s), under exclusive licence to Springer-Verlag GmbH Germany, part of Springer Nature 2021

The concept "fever of intermediate duration" (FID) was established to define prolonged fever without a concrete origin or focus, after a first evaluation, with a duration between 7 and 28 days. Nosocomial fever and immunocompromised patients are excluded from the term FID [1]. The creation of this concept had an influence on Spanish medicine but not that much outside our frontiers. Outside Spain, physicians usually prefer the term "prolonged fever" that includes all febrile syndromes lasting more than 7 days (FID and the globally admitted "classic fever of unknown origin") [2] (Fig. 1).

A transcendent article about FID was published in 2003 in Enfermedades Infecciosas y Microbiología Clínica in which they did a review of the etiology of FID, a protocol for diagnosis and management, and proposed the use of doxycycline as empiric treatment for all FID patients. The proposal to treat all FID patients with doxycycline relied on the important percentage of Q fever, rickettsiosis and brucellosis in the "old" Spanish series [3]. More recent cohorts from the south of Spain have revealed a decline in brucellosis owing to intense veterinary control in recent years. $\mathrm{Q}$ fever and rickettsiosis keep being among the most reported causes but viruses (mainly CMV but also EBV, and at a great distance parvovirus B19, HHV-6 and HIV) rise to the first places of the ranking $[4,5]$. However, A. Portillo et al. still report Coxiella burnetii and Mediterranean spotted fever (MSF) as the main causes of FID in La Rioja (north of Spain) [6]. SARS-CoV-2 should be included as the current most prevalent cause of FID all over the world [7]. Emerging viruses like dengue, chikungunya and to a lesser extent Zika should be also taken into account in areas where Aedes albopictus has been introduced like the Mediterranean

Emilio Guirao-Arrabal

emilio.guirao@gmail.com

1 Infectious Disease Unit, Hospital Universitario San Cecilio, Avenida de la Investigación s/n. 18014, Granada, Spain countries [8]. Crimean-Congo hemorrhagic fever is a tickborne viral disease that affect countries of eastern and southeastern Europe and also Spain as recently reported [9]. In Table 1, there is a list of widespread etiologies of FID and from imported and endemic causes too.

FID still accounts for a significant percentage of consultations in Infectious Disease and Internal Medicine Units of our hospitals, usually as outpatients but severe cases may be admitted too (around 5\%). Accordingly, we should reconsider which patients should receive doxycycline and which should be evaluated until they can be finally diagnosed.

First indication for empirical doxycycline treatment would be a typical MSF or TIBOLA/DEBONEL syndrome. FID with a typical rickettsial picture would be treated with doxycycline without any delay [10].

Second indication for empirical treatment is after ruling out prevalent viruses with a first serology at the first visit to our consult: CMV, EBV, parvovirus B19 and HIV. Additionally, a RT-PCR or an antigen test for SARS-CoV-2 would be mandatory in the current pandemic scenario [7]. Just like it was proposed in the paper of Antonio Rivero et al., some medical tests are basic: blood cultures (both aerobic and anaerobic), urine culture, chest X-ray, basic biochemistry (including creatinine, AST, ALT, LDH, C-reactive protein and procalcitonin if possible) and blood count. Of course, complete anamnesis and full-body exploration (including a thorough skin search for tick bites, search for peripheral lymphadenopathies, abdominal examination, exploration of the meningeal irritation signs and so on)[2]. If these first viral serologies, SARS-CoV-2 test and blood cultures, are all negative and the patient keeps on fevers, our proposal is to start doxycycline and wait to be confirmed by serology. Before starting antibiotics, a blood sample for Coxiella burnetii PCR would be of help in the first 14 days after symptoms onset and if the clinical picture is indicative of acute $\mathrm{Q}$ fever [6]. This strategy was of great interest in the 2008-2010 outbreak in the Netherlands because a serological diagnosis 
Fig. 1 Chronological classification of febrile syndromes. FSD, fever of short duration; FID, fever of intermediate duration; FUO, fever of unknown origin

Table. 1 Etiologies of FID in Europe

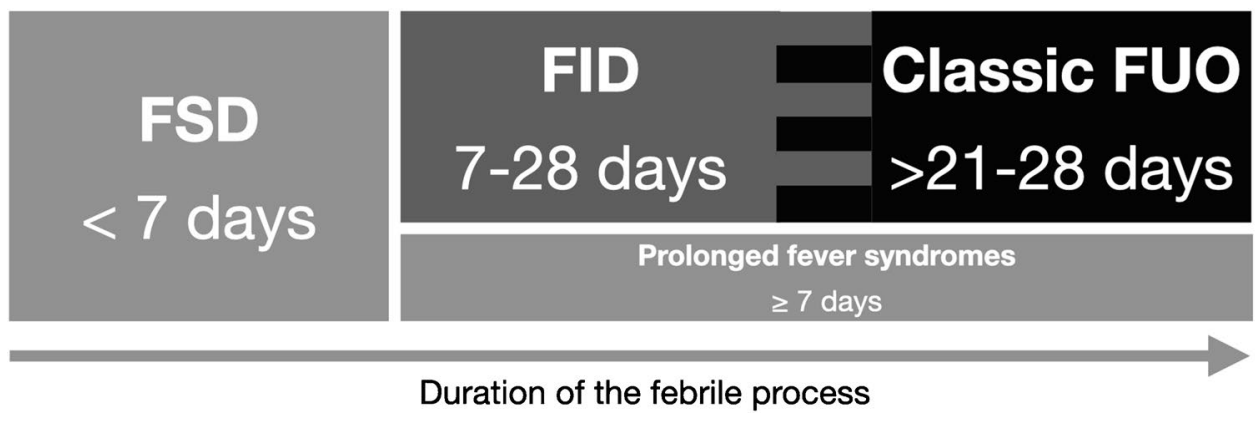

\begin{tabular}{|c|c|c|c|}
\hline & Viruses & Bacteria and mycobacteria & Parasites \\
\hline Most common etiologies & $\begin{array}{l}\text { CMV } \\
\text { EBV } \\
\text { SARS-CoV-2 }\end{array}$ & $\begin{array}{l}\text { Rickettsia } \text { spp.*** } \\
\text { Coxiella burnetiiBorrelia } \\
\text { burgdorferi }\end{array}$ & \\
\hline Less common etiologies & $\begin{array}{l}\text { HIV } \\
\text { Parvovirus B-19 } \\
\text { Human herpesvirus } 6\end{array}$ & $\begin{array}{l}\text { Occult abscessSubacute pros- } \\
\text { tatitisPyelonephritisSubacute } \\
\text { endocarditisOsteomyelitis- } \\
\text { Mycobacterium tuberculo- } \\
\text { sisLeptospira spp.Bartonella } \\
\text { henselaeAnaplasma } \\
\text { phagocytophilumFrancisela } \\
\text { tularensis**** }\end{array}$ & Toxoplasma gondii \\
\hline Unvaccinated patients & $\begin{array}{l}\text { Measles } \\
\text { Mumps } \\
\text { Rubella } \\
\text { Chickenpox }\end{array}$ & & \\
\hline $\begin{array}{l}\text { Imported and detected in } \\
\text { endemic regions }\end{array}$ & $\begin{array}{l}\text { West Nile virus disease } \\
\text { Dengue* } \\
\text { Chikungunya* } \\
\text { Zika* } \\
\text { Crimean-Congo hemor- } \\
\text { rhagic fever** }\end{array}$ & Brucella melitensis & $\begin{array}{l}\text { Leishmania infantum } \\
\text { Malaria***** } \\
\text { Babesia } \mathrm{spp} . * * * * *\end{array}$ \\
\hline
\end{tabular}

*In areas where Aedes albopictus has been detected, as an imported infection too

** In areas where Hyalomma marginatum is endemic

*** In Europe: $R$. typhi and $R$. felis which are flea-borne rickettsiosis; $R$. conorii group, $R$. helvetica, $R$. monacensis, $R$. sibirica mongolitimonae, etc. all belonging to the spotted fever group; $R$. slovaca, Candidatus Rickettsia rioja and Rickettsia raoultii related to TIBOLA/DEBONEL syndrome

***** In Spain, in Castilla y León region

****** Mostly imported can only be obtained retrospectively. Rickettsial PCR is also helpful. Although with a lower sensitivity, it has been demonstrated to be useful in patients with a negative serology (that is, in early diagnosis) $[11,12]$. The main difficulty is that this technique is not available in every hospital.

Third indication for empirical treatment would be severe sepsis or septic shock in patients with FID in which a severe form of the rickettsial disease is included in the differential diagnosis. Severe forms of MSF and other rickettsial infections can cause acute kidney injury, pneumonia, hyperbilirubinemia, hepatitis, etc. [13]. Empirical doxycycline should be initiated at admission to the hospital because delaying treatment is clearly associated with mortality [10].
Our suggestion would be not to start on doxycycline in stable patients with a low pre-test probability of a doxycycline-treatable disease if the patient can be closely monitored. The three indications for doxycycline are obviously not supported by randomized controlled trials (RCT). Certainly, RCT would be of great interest in this area to clarify the true benefit of this therapy.

There are some clues that could guide in diagnosis. There is a slight predominance for the male gender and rural origin in some rickettsial diseases, but some other like Rickettsia typhi could be more common in urban areas [14]. Some professions are at higher risk for some specific zoonosis (farmers, veterinarians, cleaning workers, etc.) [15]. The season of the year is of interest too: Rickettsia conorii, which is 
the most prevalent in Spain, has a predilection for warmer seasons like spring and summer. Rickettsia sibirica mongolitimonae also affects usually between May and September. Conversely, some other species like Rickettsia slovaca and Rickettsia rioja are much more frequent in other seasons [16]. Global warming will change all these patterns in the following years.

Analytical parameters that can be of help are lymphocytopenia (typically low in intracellular bacteria) and transaminases (high in 77\% of Q fever and rickettsiosis [5]). A moderate elevation in procalcitonin could guide the diagnosis of an intracellular bacteria as the causal agent of a FID. Lin et al. also found a procalcitonin mean of $1.05 \mathrm{ng} / \mathrm{mL}$ in a group of 189 cases of Q fever, scrub typhus and murine typhus from Taiwan [17].

Radiological explorations could be of interest especially in some infections. Chest-CT and lung ultrasound are sensitive radiological explorations for SARS-CoV-2 infection [18]. Abdominal ultrasound/CT is essential to diagnose occult abscesses and helpful to diagnose pyelonephritis [19]. PET-CT may be necessary in some cases with unresolved fever without a definitive diagnosis [20]. In case of suspecting subacute endocarditis, an echocardiography would be mandatory. Therefore, radiological explorations are important in some cases, but their performance should be gradual and argued, in order to avoid unnecessary explorations.

After starting doxycycline, an interesting issue would be re-evaluating the patient, to assess the success of the treatment, pending microbiological results and the duration of the treatment. Doxycycline for 5-7 days would be an optimal duration for most rickettsial diseases (or at least 3 days after clinical improvement) and 14 days for acute $\mathrm{Q}$ fever [10, 21].

In summary, FID has a variety of different etiologies that differ between regions, and doxycycline-treatable diseases need to be screened taking into account clinical data, and analytical and microbiological results can be received only 2-3 days after the first evaluation of the patient. Because most of the data are derived from Spanish cohorts, we cannot generalize our indications about the use of doxycycline. We therefore encourage European groups from other countries to analyse and report their data.

Author contribution All authors made substantial contributions to the writing and revision of the manuscript.

Availability of data and material Not applicable.

Code availability Not applicable.

\section{Declarations}

Competing interests The authors declare no competing interests.

\section{References}

1. Bernabeu-Wittel M, Pachón J, Alarcón A, López-Cortés LF, Viciana P, Jiménez-Mejías ME et al (1999) Murine typhus as a common cause of fever of intermediate duration. Arch Intern Med 159:872. https://doi.org/10.1001/archinte.159.8.872. http:// archinte.jamanetwork.com/article.aspx?doi=10.1001/archinte. 159.8.872

2. Petersdorf RG, Beeson PB (1961) Fever of unexplained origin: report of 100 cases. Medicine 40:1-30. https://doi.org/10.1097/ 00005792-196102000-00001. http://journals.lww.com/00005 792-196102000-00001

3. Rivero A, Zambrana JL, Pachón J (2003) Fiebre de duración intermedia. Enferm Infecc Microbiol Clin 21:147-152. https:// doi.org/10.1016/S0213-005X(03)72904-8

4. Espinosa N, Cañas E, Bernabeu-Wittel M, Martín A, Viciana P, Pachón J (2010) The changing etiology of fever of intermediate duration. Enferm Infecc Microbiol Clin 28:416-420. https://doi. org/10.1016/j.eimc.2009.07.014

5. Parra Ruiz J, Peña Monje A, Tomás Jiménez C, Parejo Sánchez MI, Vinuesa García D, Muñoz Medina L et al (2008) Clinical spectrum of fever of intermediate duration in the south of Spain. Eur J Clin Microbiol Infect Dis 27:993-995. https://doi.org/10. 1007/s10096-008-0530-6

6. Portillo A, Fernández M, Metola L, Sanz M, Blanco J, Ugalde E et al (2016) Rickettsia spp. and Coxiella burnetii among the most frequent causative agents of fever of intermediate duration in the north of Spain. Clin Res Infect Dis 3:3-5

7. Huang C, Wang Y, Li X, Ren L, Zhao J, Hu Y et al (2020) Clinical features of patients infected with 2019 novel coronavirus in Wuhan, China. The Lancet 395:497-506. https://doi.org/10. 1016/S0140-6736(20)30183-5

8. Portillo A, Ruiz-Arrondo I, Oteo JA (2018) Artrópodos vectores en España y sus enfermedades transmisibles. Med Clin 151:450-459. https://doi.org/10.1016/j.medcli.2018.06.021

9. Negredo A, Sánchez-Arroyo R, Díez-Fuertes F, de Ory F, Budiño MA, Vázquez A et al (2021) Fatal case of CrimeanCongo hemorrhagic fever caused by reassortant virus, Spain, 2018. Emerg Infect Dis 27:1211-1215. https://doi.org/10.3201/ eid2704.203462

10. Biggs HM, Behravesh CB, Bradley KK, Dahlgren FS, Drexler NA, Dumler JS et al (2016) Diagnosis and management of tickborne rickettsial diseases: rocky mountain spotted fever, ehrlichioses, and anaplasmosis -- United States. MMWR Recommendations and Reports 65:1-44

11. Znazen A, Sellami H, Elleuch E, Hattab Z, ben Sassi L, Khrouf F et al (2015) Comparison of two quantitative real time PCR assays for rickettsia detection in patients from Tunisia. PLoS Negl Trop Dis 9:1-9. https://doi.org/10.1371/journal.pntd.0003487

12. Bolaños-Rivero M, Carranza-Rodríguez C, Hernández-Cabrera M, Pisos-Álamo E, Jaén-Sánchez N, Pérez-Arellano JL (2017) Usefulness of the early molecular diagnosis of Q fever and rickettsial diseases in patients with fever of intermediate duration. Enferm Infecc Microbiol Clin 35:655-658. https://doi.org/10. 1016/j.eimc.2016.02.026

13. Oteo JA, Portillo A (2012) Tick-borne rickettsioses in Europe. Ticks Tick Borne Dis 3:271-278. https://doi.org/10.1016/j.ttbdis. 2012.10.035. http://www.ncbi.nlm.nih.gov/pubmed/23177355

14. Bolaños-Rivero M, Santana-Rodriguez É, Ángel-Moreno A, Hernández-Cabrera M, Limiñana-Canal JM, Carranza-Rodríguez C et al (2011) Seroprevalence of Rickettsia typhi and Rickettsia conorii infections in the Canary Islands (Spain). Int J Infect Dis 15:481-485. https://doi.org/10.1016/j.ijid.2011.03.019 
15. Dutkiewicz J, Cisak E, Sroka J, Wójcik-Fatla A, Zajac V (2011) Biological agents as occupational hazards - selected issues. Ann Agric Environ Med 18:286-293

16 Oteo JA, Ibarra V, Blanco JR, Metola L, Vallejo M, Martínez De Artola V (2003) Epidemiological and clinical differences among DEBONEL-TIBOLA and other tick-borne diseases in Spain. Ann N Y Acad Sci 990:391-2. https://doi.org/10.1111/j.1749-6632. 2003.tb07397.x

17. Lin IF, Lin JN, Tsai CT, Wu YY, Chen YH, Lai CH (2020) Serum $\mathrm{C}$-reactive protein and procalcitonin values in acute $\mathrm{Q}$ fever, scrub typhus, and murine typhus. BMC Infect Dis 20:1-11. https://doi. org/10.1186/s12879-020-05058-8

18. Islam N, Ebrahimzadeh S, Salameh JP, Kazi S, Fabiano N, Treanor L et al (2021) Thoracic imaging tests for the diagnosis of COVID-19. Cochrane Database Syst Rev 2021. https://doi.org/ 10.1002/14651858.CD013639.pub4

19. Emmi V, Sganga G (2009) Clinical diagnosis of intra-abdominal infections. J Chemother 21:12-18. https://doi.org/10.1179/joc. 2009.21.supplement-1.12
20. Jaruskova M, Belohlavek O (2006) Role of FDG-PET and PET/CT in the diagnosis of prolonged febrile states. Eur J Nucl Med Mol Imaging 33:913-918. https://doi.org/10.1007/s00259-006-0064-Z

21. Frieden TR, Harold Jaffe DW, Director for Science James Stephens AW, Moolenaar RL, Series Christine Casey MG, Boyd MF, et al. Diagnosis and Management of Q Fever — United States, 2013 Recommendations from CDC and the Q Fever Working Group Morbidity and Mortality Weekly Report Centers for Disease Control and Prevention MMWR Editorial and Production Staff MMWR Editorial Board. MMWR 2013;6262. http://www.cdc. gov/mmwr/cme/conted.html

Publisher's note Springer Nature remains neutral with regard to jurisdictional claims in published maps and institutional affiliations. 